\title{
Na morte da ovelha Dolly Requiem pelos rescaldos de um teatro "clónico"
} Guillermo Heras

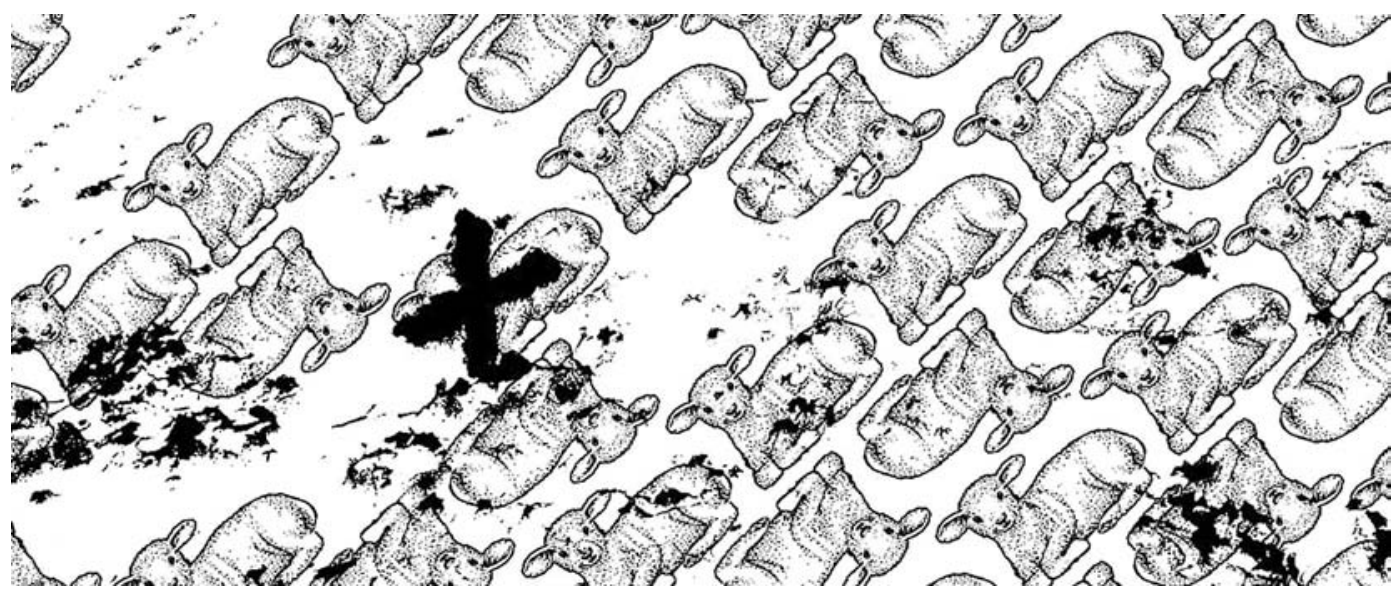

Ao longo de todo o ano de 2003 acumularam-se muitas notícias más. Algumas de uma dimensão mundial que, sem dúvida, irão alterar a sempre maltratada "ordem mundial". Ter assistido a uma das guerras mais obscenas e injustificadas dos últimos tempos será um facto que deixará para sempre marcadas as nossas vidas a fim de enfrentar esse futuro incerto que nos tocará atravessar entre sobressaltos e disposições vazias de conteúdo.

Outra notícia que invadiu as primeiras páginas da imprensa de todo o mundo foi a morte desse pequeno animal criado por clonagem e chamado "ovelha Dolly". Uma das hipóteses que se formulam como diagnóstico da sua morte prematura é a aceleração excessiva do seu processo de envelhecimento. Algo semelhante está a passar-se recentemente com certas formas cénicas que durante alguns anos se tornaram o cânone dominante para certos sectores da profissão teatral, centrados sobretudo num segmento de programadores de festivais internacionais e uma minoria de críticos "iluminados", que acreditaram que lutar contra o conservadorismo dominante era aceitar como boa qualquer linguagem cénica cujo suporte eram as narrativas desconstruidas ou as puras alternativas dominadas pela imagem e pela exclusão do texto.

Por ser um firme defensor da investigação, da procura e da experimentação ligadas aos fenómenos cénicos, sempre me parecerá interessante qualquer criador que se coloque à beira do abismo e tente ultrapassar formas de expressão teatrais arcaicas, tão presentes nos repertórios das nossas cidades ocidentais. Contudo, outra coisa bem diferente é a praga de predadores e plagiadores que abundam em todo o mundo, conseguindo depreciar rapidamente qualquer achado inovador em função da criação rápida de uma moda. É a peste do "teatro clónico". E, como lembrança desta morte prematura anunciada que pode ter este teatro, gostaria de recuperar dois escritos surgidos no breve período de dois anos e que podem situar um certo diagnóstico do que penso - trata-se portanto de algo subjectivo, passional e talvez pouco relevante acerca dos fenómenos transitórios que podem constituir hoje uma alternativa passivel de ser considerada transgressiva, mas que se justificam apenas do ponto de vista formal como sendo próprios de um mercado, apesar de disfarçado de "mercado alternativo".

Algumas reflexões sobre o teatro clónico, ou de como a ovelha Dolly pode balir em qualquer cenário, ou as quinze fórmulas infalíveis para produzir um espectáculo para ser programado num festival internacional.

Já há bastantes anos, e devido sobretudo a dois fenómenos básicos, a proliferação de festivais de artes cénicas internacionais e a rápida propagação dos suportes das novas tecnologias que fazem fluir a informação visual de uma maneira praticamente imediata, podemos afirmar que se criou um determinado tipo, modelo ou fórmula de espectáculo que muito deve a este circuito que permite a compreensão (ou descodificação) plausivel desde o extremo sul da América Latina até às distantes terras do Oriente, das cidades africanas ou europeias e, porque não, desde os Estados Unidos à América Central, passando pelos Pólos e pelas extensas terras da Rússia, da China ou da Índia. Somos já transnacionais, entendemos uma proposta do Uzbequistão ou de Lima, de Tijuana ou de Rabat, de Pequim ou de Montréal, porque afinal só parece haver dois caminhos para que estes espectáculos sejam 
apresentados na rede dos festivais internacionais: ou são profundamente antropológicos, folclóricos ou específicos de uma certa cultura, ou são propostas "clónicas" emanadas de um imaginário cénico, geralmente criado pelos artistas que estão na moda e rapidamente louvado pelos programadores destes eventos universais e, portanto, ponto de referência para outras propostas que desejam entrar no festim festivaleiro.

Trata-se de uma situação delicada, porque com este raciocínio poderia pensar-se que estou contra a "contaminação", a mestiçagem ou a influência reciproca entre várias linguagens artísticas. Nada está mais longe da realidade, pois creio que uma das renovações mais importantes do teatro virado para o futuro passa por assumir essas influências e intercâmbios como algo de natural e positivo. Algo de bom haveria de ter a globalização... Já que nos traz bastante prejuizo do ponto de vista económico, pelo menos do ponto de vista cultural é bom que nos possa servir como confronto dialéctico da criação, sobretudo a partir das ferramentas que nos proporcionam essas novas tecnologias.

Todavia, uma coisa creio que seja a influência de uma linguagem artística sobre outra, e a posterior elaboração e sintese com as suas próprias "chaves", e uma outra fazer pura e simplesmente espectáculos "clónicos" segundo o modelo "ovelha Dolly", baseados apenas numa cópia do que está na moda. Claro que nem sequer estou a falar num conflito tão actual no mundo da literatura como o tema do plágio ou da cópia. Aqui entrariamos numa ramificação de problemas, e talvez o mais importante seja de ordem económica, ou seja o dos "direitos de autor". No âmbito teatral, refiro-me a algo tão grosseiro como a substituição de qualquer tentativa para se assegurar o produto final através de uma determinada fórmula que já está garantida pelo mercado, ainda que neste caso o mercado seja o do "novo teatro", da "nova dramaturgia" ou, o que já resulta mais pretensioso, das "linguagens transgressivas". Aqui o tema seria mais de ordem moral. Mas é licito utilizar essa palavra na actualidade?

Nos últimos tempos a ausência, retirada ou desaparição dos grandes mestres talvez tenha permitido preencher 0 seu lugar por um grupo de criadores interessantes, mas sem uma linguagem tão definida, tão autêntica como a desses grandes artistas da cena. Logo a seguir, muitos outros se lançaram na reprodução do modelo que funcionava, dai que a exposição a alguns desses trabalhos vistos em continuidade me produzam o efeito das "lojas dos trezentos" (isto antes do euro). Existe técnica, preparação e inclusive design, porém falta discurso.

Assim sendo, as fórmulas que proponho a seguir logicamente com uma carga irónica - são fruto da minha experiência ao longo de 2001, ano em que assisti a um número relevante destes festivais internacionais, quer neste lado do mundo, quer no continente americano.

Fórmulas para ser contratado para um festival internacional na seç̧ão dos espectáculos "clónicos":
1. Juntar na representação toda uma série de textos dispersos e que falem das coisas mais dispares. Se for possivel, os actores ou bailarinos deveriam ser de diferentes paises e cada um deveria falar na sua própria língua. Não importa que o espectador não entenda nem o que se diz, nem como se diz... é um valor acrescentado que assim seja para a teoria da recepção: uma aposta clara na confusão.

2. Os actores devem sempre dar a impressão de não estarem a representar, mas sim a viverem. Às vezes, os mesmos criadores do espectáculo preferem que os actores não possuam nenhuma técnica, pois trata-se de ser "absolutamente livres" na cena. Como se a liberdade do actor não viesse justamente do domínio de uma técnica e de um ofício... A respeito deste ponto, muitos programadores têm em alta consideração o facto de os actores serem amateurs ou de etnias primitivas, que conferem um ar simplório ao resultado final.

3. É imprescindivel que nestas propostas haja pelo menos um ou dois microfones de pé para que os actores se dirijam directamente ao público. Como a personagem é o actor, nem sequer poderiamos falar em "distanciação", mas antes em saturação do que se quer dizer: "Não estamos a representar" ou "Isto não é uma representação". É o sonho, desde sempre, de derrubar a "quarta parede" pela interpelação do público, esquecendo que no velho cabaret isto se faz de maneira muito mais radical, e inclusive participativa.

4. É um valor acrescentado trabalhar com estéticas rétro, sobretudo dos anos 60 e 70 . Claro que desta época se retira apenas o acessório: ícones, trajes, músicas... nunca os discursos ideológicos.

5. Utilização de diálogos e falas textuais insolentes. A maior quantidade de terminologia testicular, ovarial, insultos, jargão canalha e outras variantes dos palavrões ordinários, muitos mais aptos para entrar na categoria da transgressão. Algo como "cocó, cu, chichi" das crianças quando apreendem a falar.

6. Reprodução em directo da vida quotidiana, de preferência da comida e das suas variantes gastronómicas. Nestes espectáculos, quase sempre se cozinha ou se utilizam todos os tipos de verduras e hortaliças para, geralmente, serem lançadas entre os vários executantes da representação. São muito apreciados nos últimos espectáculos que vi: os ovos, as alfaces e o molho de tomate.

7. Nestas propostas abordam-se aqueles que se costumam chamar "temas politicamente incorrectos", que normalmente só costumam incomodar a parte mais pacata e conservadora do público, o que faz com que haja poucas deserções entre esses espectadores cultos que foram ver uma função moderna. 0 incorrecto costuma tornar-se correctíssimo por não haver nenhum aprofundamento do que se enuncia, pois é quase um slogan publicitário.

8. É muito importante que nestes espectáculos haja um misturador musical em directo, manipulado por um músico ou pelos próprios actores, a fim de se produzir todo o tipo de efeitos sonoros ao longo da representação. Costuma cair muito bem contrastar esta música electro- 
acústica com um repertório de músicas sub-culturais (boleros, rancheras, pasodobles...).

9. Gosto pelo mau gosto. Estética de películas gore ou comics violentos. A fealdade como valor acrescentado.

10. Contínuas referências culturais nos textos falados. $\mathrm{Ou}$, dito de outra maneira, "a intertextualidade ao poder". Nesta linha incluem-se autores fétiche do romance, poesia, filosofia ou guião cinematográfico que continuamente são citados explicitaa ou implicitamente, apesar de os seus nomes não aparecerem nos créditos.

11. Ultimamente as cenas encheram-se de animais - peço desculpa - já que me refiro a autênticos animais da fauna do Senhor (patos, rãs, burros, coelhos, cães, galinhas, serpentes, papagaios e outras espécies tropicais). Parece que apesar dos protestos dos programadores, sobretudo pelo facto de as cenas se encherem de merda, afinal obtém-se um valor acrescentado devido à fisicalidade destes animais.

12. Ruptura da narração oral na encenação com contínuas sequências influenciadas pela "dança contemporânea". Quanto maior o grau de convulsão corporal, maior excitação valorativa. 0 interdisciplinar banaliza-se, mas muitos jovens espectadores acham que estão numa discoteca e, felizmente, não num teatro.

13. Antologia de "obviedades" nas analogias e metáforas dos materiais utilizados, por exemplo, molho de tomate ou ketchup como sangue, água como urina, farinha como cocaina, etc.

14. Ambiguidade total do discurso social e político utilizado. Nunca saberemos se o que nos é dito é uma crítica ao fascismo ou se o espectáculo é directamente parafascista.

15. Como consequência do ponto anterior, o resultado são espectáculos "sem ideologia" - algo impossível -, isto é, absolutamente auto-complacentes com a estética e a ética do que se está a mostrar. A autocrítica é uma palavra inexistente no dicionário dos espectáculos "clónicos".

Claro que depois destas reflexões receio que deixem de me convidar para festivais internacionais e que os seguidores do "teatro clónico" me atirem com o termo fétiche do seu vocabulário: "És um antiquado".

Contudo, se analisassem um pouco mais, talvez se dessem conta de que, no pior dos casos, a única coisa que estas linhas escondem é uma frustração por não ser incluído na programação dos festivais internacionais e uma admiração pelos primeiros que puseram em movimento, com rigor e convicção, algumas propostas carregadas de renovação, mas que copiada pelos seus seguidores se converteram em imagens patéticas de um museu de cera.

De qualquer maneira, creio que o que pulsa no fundo é o equívoco entre arte de vanguarda e arte contemporânea. Sendo absolutamente necessária a contínua aparição de uma certa vanguarda cultural, o que nunca se deveria produzir é a sua canonização. Gosto da vanguarda como uma possivel estratégia de construção de um discurso artístico, mas esta não deveria excluir outras possibilidades igualmente válidas para produzir contemporaneidade.

Como muito bem assinalava Anatxu Zabalbeascoa,

numa crítica ao livro de Juan José Sebreli, As aventuras da vanguarda publicada no El País: "A vanguarda é o esquecimento. 0 efémero e o obscuro são para Juan José Sebreli duas das cenas características comuns a todas as expressões deste fenómeno 'que despreza não só quem compreende unicamente o superficial, mas também todos aqueles que pretendem racionalmente entender o que é profundo'".

$E$, no entanto, hoje já não podemos entender a evolução das Artes Cénicas desde o começo do século XX sem as apaixonantes, mesmo que contraditórias, aventuras das vanguardas.

Contudo, talvez porque deveríamos situar a vanguarda como um "conceito histórico", gostaria de descer ao terreno da realidade e assinalar algumas reflexões sobre as possibilidades de encontrar referências sobre a prática de uma cena actual, e por isso proponho:

Vinte e um conceitos que não se deveriam admitir num autêntico teatro contemporâneo

0 teatro contemporâneo:

1. Não admite censura de nenhum tipo.

2. Não admite gurus intocáveis.

3. Não admite ortodoxias intransigentes.

4. Não admite nenhum tipo de intolerâncias.

5. Não admite nacionalismos redutores.

6. Não admite paternalismos babosos.

7. Não admite pedanterias estéreis.

8. Não admite a falta de pensamento.

9. Não admite soberbas infantis.

10. Não admite a falta de rigor na sua escrita.

11. Não admite a exclusão de géneros.

12. Não admite a crítica conservadora nem a conformista.

13. Não admite encenadores cobardes.

14. Não admite actores retóricos.

15. Não admite informadores mediáticos frivolos.

16. Não admite um espectador que não seja co-criador.

17. Não admite programadores intolerantes.

18. Não admite os sistemas de ensino em uso.

19. Não admite as modas nem os seus abusos.

20. Não admite as fórmulas infaliveis.

21. Não admite os choros nem as lamentações.

E, por tudo isso, um autêntico teatro contemporâneo deveria ser: livre, aberto, plural, arriscado, diferente, investigador, autocrítico, comprometido, artesanal, mestiço e interdisciplinar.

\section{Referência bibliográfica}

SEBRELI, Juan José (2003), As aventuras da vanguarda, Madrid, Sudamericana.

Tradução de Sebastiana Fadda e Neus Lagunas 